\title{
Digital Educational Game for Children With Type 1 Diabetes
}

\author{
Charalampos Kyfonidis \\ University of Strathclyde \\ Computer and Information Sciences \\ 16 Richmond St, G1 1XQ, UK \\ c.kyfonidis@strath.ac.uk
}

\author{
Marilyn Lennon \\ University of Strathclyde \\ Computer and Information Sciences \\ 16 Richmond St, G1 1XQ, UK \\ marilyn.lennon@strath.ac.uk
}

\begin{abstract}
A big number of children live with managing Type 1 diabetes. Those children need guidance and knowledge near to diagnosis and during ongoing management in order to cope with their condition. This paper presents the motivation and methodology for the user centered design and development of a digital educational game that will help children aged 5 and younger manage Type 1 diabetes. The game will educate children on the main concepts related to their disease, the way the they interact with each other and how their lifestyle can help them control and manage these symptoms. The game is designed to educate and also to empower the user and their families to manage and control their diabetes.
\end{abstract}

Type-1 Diabetes, Children, Empowerment, Educational Game

\section{INTRODUCTION}

In 2014 around 33,500 children under the age of 19 in the UK had Type-1 Diabetes (T1D) ${ }^{1}$. Diabetes is a serious disease that requires constant management. It is well documented that if a childs diabetes is not looked after, this will adversely affect their learning, ability and health ${ }^{2}$. Hence, appropriate initial engagement and education, close to diagnosis, is important to prevent later mis-management and health complications (Aoki et al. (2004)).

An effective approach for the education of children with T1D is educational games that introduce healthy lifestyle choices. It is a relatively unexplored research field that combines Human Computer Interaction, Psychology, Education and Sociology. It is stated in the literature that serious games that challenge and educate are effective in increasing compliance in diabetes treatment (Kharrazi et al. (2009)). Moreover, video games for diabetes education can be intrinsically motivating and can be more effective than traditional interventions when it comes to changing behaviour or maintaining healthy behaviour (DeShazo et al. (2010)).

\footnotetext{
${ }^{1} \mathrm{https}: / /$ www.diabetes.org.uk/Documents/About

Us/Statistics/Diabetes-key-stats-guidelines-April2014.pdf

${ }^{2}$ http://www.diabetes-scotland.org/ggc/documents/pdf_files/20120525

Supporting Children and Young People with Diabetes in Education.pdf
}

Currently very few games are available that match the goals of younger T1D patients (DeShazo et al. (2010)), who are just beginning to learn about their condition and how to manage it. The main goal of this project is to design and evaluate a digital educational game that will empower and motivate young children with T1D to cope and learn to effectively manage their disease. This paper presents a brief overview of related work and introduces the methodology that will be used to design the game with and for children with T1D, their friends and family and health professionals involved in their care.

\section{RELATED WORK}

The first game targeting children with T1D was Captain Novolin. It was released in 1992 by Raya Systems for Nintendo SNES platform. The game was evaluated by 8-14 years old children and their parents for its usability but not directly for its educational aspects (Lieberman (1997)). Packy \& Marlon was another game for Nintendo SNES released in 1995 and was more sophisticated than Captain Novolin. It was evaluated with children 816 years old with T1D and was found to increase self-efficacy, communication with parents, disease management and decrease urgent doctor visits (Brown et al. (1997)).

Starbright Life Adventures and Dbaza Diabetes Education for Kinds were interactive CD-ROMs 
launched in 1999 and 2003 respectively. They were evaluated with 5-10 years old children and showed significant results in increasing diabetes knowledge ${ }^{3}$ (Halvorson et al. (1999)).

Comprehensive work was done by Aoki et al. (2004, 2005) by creating a series of four educational games for featured phones. Insulot was a slot machine game teaching the child about the interaction between insulin and carbohydrates. Egg Breeder and Detective were focused on educating about the management of the disease and lastly, Magic Toom was focusing on nutritional education. Insulot was found to be useful and likable and the other three were found to be useful, entertaining and "clinically useful" (DeShazo et al. (2010)).

Another interesting game called $G R I P^{4}$ was released in 2008 by RANJ Serious Games co. The game is an online flash player game and focuses on the consequences of blood sugar level. GRIP won in 2008 the "Top Innovation Award" in Netherlands. Unfortunately, it is only available in Dutch.

More recent approaches based on smartphone technologies are Carb Counting with Lenny and Monster Manor. The first is a iPhone app that educates about nutritional facts. The later is an Android game that is integrated with the BlueLoop diabetes tracking app, and focuses on diabetes management through behaviour change. It gives rewards to the users for uploading their blood glucose levels to the game ${ }^{5}$.

Unfortunately, most of these games require reading skills from the children, a fact that results in excluding younger children from the target group. Moreover, all of these where developed to be used outside the clinical setting, an interesting fact considering that education is more effective inside clinical settings Murphy et al. (2006).

The next section introduces the approach and methodology for the requirements gathering of a game for preschool children with T1D. The game will be designed to both educate and empower children and their families.

\section{METHODOLOGY}

In order to produce a thorough game that will be effective and used in the standard practice, a stakeholder-centered design methodology approach was chosen.

\footnotetext{
${ }^{3} \mathrm{http}: / /$ www.dbaza.com/dek/testing.html

${ }^{4}$ http://www.ranj.com/content/werk/grip\#.VpjCtFJNtnR

${ }^{5} \mathrm{http}: / /$ ayogo.com/blog/monster-manor/
}

This methodology can be decomposed in three distinct phases:

\section{Requirements Phase}

\section{Design \& Implementation Phase}

\section{Evaluation Phase}

Figure 1 presents the three phases of the project. During the whole life-cycle of the project people will participate in every phase, informing the design and evaluation of the game. The participants are all the T1D education stakeholders: parents, children, diabetes clinicians (consultants, nurses, dietitians) and Scottish government staff responsible for diabetes. This way we can understand the existing "eco-system" and build upon it.

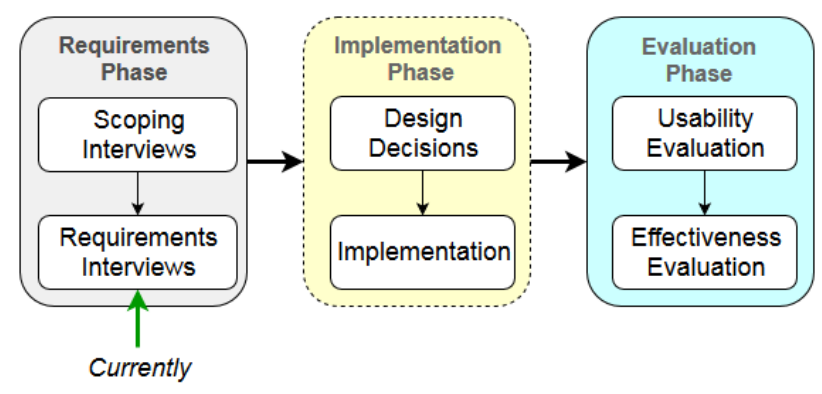

Figure 1: Different phases of the project and the potential involvement of T1D stakeholders (Parents, Patients, Health and Education Professionals).

\subsection{Design}

In order to elicit the requirements for such a game, we decided to follow a user-centered design approach. Namely, we are currently conducting a set of requirements gathering and scoping interviews with T1D education stakeholders.

\subsubsection{Scoping Interview}

The first scoping interview (June 2015) was with a consultant pediatrician for children with T1D in Glasgow, who had many years of experience in different positions of the diabetes care (government, charities and primary care).

The participant shared his concerns about the current practices and confirmed lack of ageappropriate education for younger children with T1D. Moreover, he urged towards the need for a more attractive way to educate younger children patients about the cause and effects associated with managing diabetes. He suggested that the focus of such a game should be in the three main concepts of diabetes (food intake, insulin and exercise) and how those interact with each other and impact the condition. 
This interview helped in formulating the scope which can be summarised as follows:

- Age group would be preschool children who do not have literacy skills and thus cannot access information.

- The game would be based inside the clinical setting, in order for the clinicians and parents to be involved as well in the process.

- The game will focus on the three basic concepts of diabetes management and how those three interact with each other.

\subsubsection{Requirements Interviews}

After determining the scope, we are currently conducting a set of interviews in order to elicit the requirements for the game. The evidence from those interviews will inform the design and help build a game in accordance with the current "eco-system".

Since young children of this age not able to set their own learning goals, feedback from those who are educating them is very important(Scaife et al. (1997)). Hence, care professionals, teachers, parents and staff from government organisations, will be interviewed. The knowledge and experiences of the participants will uncover the health, education and lifestyle needs of the children with diabetes. Those needs would be thereafter translated into the requirements for the game. Those requirements would consist of all the non-functional goals which are related to the education about the disease.

\subsection{Implementation}

The requirements gathering will help in the production of the functional requirements (usecases). The usecases produced will feed into the production of storyboards and these storyboards will be formally evaluated with family personas (representative imaginary families) and lead in the creation of the first full paper prototypes for the game. Those prototypes will be evaluated with potential users (children, parents and clinicians), refined and ultimately guide the implementation. During the implementation rapid prototyping will allow the testing of the game and its content with potential users, in order to eliminate any major usability flaws at an early stage.

\subsection{Evaluation}

A final summative evaluation study will be designed and conducted to investigate both the usability and user experience of the game and also to evaluate the game in terms of effectiveness.

The usability aspects are related to satisfaction, fun, acceptability, devotion. The effectiveness aspects are related to learning outcomes and self-efficacy. Some of those outcomes can be measured through questionnaires and others through device logging data. Moreover, the effectiveness measurements will be done before the patients use the game and after a few educational sessions with it.

The measurement of such indicators by asking children at that age might be difficult. Alternatively, those measurements could be addressed in part through the parents, health and school professionals. Since, those people are responsible for the education about the disease, they can monitor the child's overall progress and report it.

\section{CONCLUSION}

This paper presented the motivation and methodology for designing and building an educational game for preschool children with T1D. The game will potentially motivate and empower children to cope and learn to effectively manage their disease.

The role of the T1D stakeholders in the project is essential since they will take part in all the phases of its development and will be treated both as informants and design partners (Druin (2002)). The game will be designed and implemented based on the children's needs and conceptions. Finally, it will be evaluated for its learning effectiveness and usability.

\section{REFERENCES}

Aoki, N., S. Ohta, H. Masuda, T. Naito, T. Sawai, K. Nishida, T. Okada, M. Oishi, Y. Iwasawa, K. Toyomasu, et al. (2004). Edutainment tools for initial education of type- 1 diabetes mellitus: initial diabetes education with fun. Medinfo 11(Pt 2), 855-9.

Aoki, N., S. Ohta, T. Okada, M. Oishi, and T. Fukui (2005). Insulot a cellular phone-based edutainment learning tool for children with type 1 diabetes. Diabetes care 28(3), 760-760.

Brown, S. J., D. A. Lieberman, B. Gemeny, Y. C. Fan, D. Wilson, and D. Pasta (1997). Educational video game for juvenile diabetes: results of a controlled trial. Informatics for Health and Social Care 22(1), 77-89.

DeShazo, J., L. Harris, and W. Pratt (2010). Effective intervention or child's play? a review of video games for diabetes education. Diabetes technology \& therapeutics 12(10), 815-822.

Druin, A. (2002). The role of children in the design of new technology. Behaviour and information technology 21(1), 1-25. 
Halvorson, M., F. Kaufman, and R. Engilman (1999). Comparison of a diabetes cd-rom program, diabetes video game and diabetes kids class in diabetes management and knowledge acquisiton in children ages 5-10 with type 1 diabetes. In Diabetes, Volume 48, pp. A73-A73.

Kharrazi, H., A. Faiola, and J. Defazio (2009). Healthcare game design: behavioral modeling of serious gaming design for children with chronic diseases. Human-Computer Interaction. Interacting in Various Application Domains, 335344.

Lieberman, D. A. (1997). Interactive video games for health promotion: Effects on knowledge, selfefficacy social support, and health. street, richard I. jr.; gold, william r.

Murphy, H., G. Rayman, and T. Skinner (2006). Psycho-educational interventions for children and young people with type 1 diabetes. Diabetic Medicine 23(9), 935-943.

Scaife, M., Y. Rogers, F. Aldrich, and M. Davies (1997). Designing for or designing with? informant design for interactive learning environments. In Proceedings of the ACM SIGCHI Conference on Human factors in computing systems, pp. 343350. ACM. 